\title{
OS CENTROS FEDERAIS DE EDUCAÇÃO TECNOLÓGICA E O ENSINO SUPERIOR: DUAS LÓGICAS EM CONFRONTO*
}

\author{
Maria CiavatTa \\ O novo é o aprendizado intelectual.
}

(Acácia Kuenzer, 2005)

\begin{abstract}
RESUMO: O sentido educacional que os Centros Federais de Educação Tecnológica assumem ao se tornarem, progressivamente, instituições de ensino superior, exige que se defina que ser humano se quer formar e a que finalidades se destina a educação. Cabe ainda uma reflexão sobre a questão da técnica, da ciência e da tecnologia e sua relação com o trabalho e a educação. Tendo como horizonte uma visão de totalidade social dos fenômenos, nas múltiplas relações que estabelecem, portanto, na sua complexidade, trataremos do tema proposto em sua dimensão histórica e política. Primeiro, refletimos sobre o significado da técnica e sua relação com o conhecimento, a ciência e as tecnologias. A seguir, trataremos dos termos cidadão produtivo e/ou emancipado e da estrutura social brasileira e suas grandes desigualdades. Por último, da questão da universidade, da produção do conhecimento e de sua relação com o ensino médio e a formação de tecnólogos em nível superior.
\end{abstract}

Palavras-chave: Ensino superior. Técnica, ciência e tecnologia. Cidadão produtivo. Tecnólogo.

* Este texto foi apresentado, em versão preliminar, no Seminário "CEFETS e a Universidade Tecnológica” (Brasília: CEFET-MG/MEC-SETEC, 25-26 out. 2005) e tem por base a pesquisa $\mathrm{Me}$ mória e temporalidades da formação do cidadão produtivo emancipado. Do ensino médio técnico à educação integrada profissional e tecnológica (2005-2007) (Universidade Federal Fluminense, Programa de Pós-graduação em Educação. Bolsa de Produtividade em Pesquisa, CNPq E FAPERJ).

** Doutora em Ciências Humanas (Educação) pela Pontifícia Universidade Católica do Rio de Janeiro (PUC-RJ) e professora titular do Programa de Pós-graduação em Educação da Universidade Federal Fluminense (UFF).E-mail: mciavatta@terra.com.br

Educ. Soc., Campinas, vol. 27, n. 96 - Especial, p. 911-934, out. 2006

Disponível em <http://www.cedes.unicamp.br> 
Os Centros Federais de Educação Tecnológica e o ensino superior...

THE FEDERAL CENTERS OF TECHNOLOGICAL EDUCATION AND HIGHER EDUCATION: TWO CONFRONTING LOGICS

ABSTRACT: As the Federal Centers of Technological Education gradually become higher education institutions the educational meaning they assume requires a definition of which human being we want to form and what purposes education serves. A reflection about the issue of technique, science and technology and their relation to work and education is also needed. Seeking a vision of social totality of the phenomena, in their multiple relations, therefore, in their complexity, we tackle the proposed subject in its historical and political dimension. We first reflect on the meaning of technique and its relation to knowledge, science and technologies. We then approach the terms productive and/or emancipated citizen and the Brazilian social structure, marked by great inequalities. Finally, we raise the issues of universities and production of knowledge and their relation to senior high school and the education of technologists on a higher level.

Key words: Higher education. Technique. Science and technology. Productive citizen. Technologist.

\section{Introdução}

A

síntese da utopia sobre o ser humano é a sua humanização, processo permanente de resistir à própria tendência a se corromper, a se destruir, a se desumanizar e a desumanizar os outros. A defesa da educação emancipadora tem como inspiração essa idéia necessária, mas de difícil realização.

No plano nacional, entendemos que essa utopia estaria expressa no art. $3^{\circ}$ da Constituição Federal de 1988 que constitui como objetivos fundamentais da República "I - construir uma sociedade livre, justa e solidária; II - garantir o desenvolvimento nacional; III - erradicar a pobreza e a marginalização e reduzir as desigualdades sociais e regionais; IV - promover o bem de todos, sem preconceitos de origem, raça, sexo, cor, idade e quaisquer outras formas de discriminação". Não é sem razão que a mesma Constituição, no seu art. n. 205, prevê que a educação deve visar "ao pleno desenvolvimento da pessoa, seu preparo para o exercício da cidadania e sua qualificação para o trabalho".

A discussão sobre o sentido educacional que os Centros Federais de Educação Tecnológica assumem ao se tornarem, progressivamente, 
instituições de ensino superior, exige que se defina que homem e que mulher se quer formar, a que finalidade se destina a educação. De outro lado, cabe uma reflexão sobre a questão da técnica, da ciência e da tecnologia e sua relação com o trabalho e a educação. Particularmente, supõe que se considerem suas conseqüências para a humanização ou a realização de todo o potencial humano em um mundo dominado, material e ideologicamente, pelo lucro fácil, pelas guerras e pela destruição da natureza e a desumanização das condiçôes de vida dos povos. $\mathrm{O}$ modo capitalista de produção da existência, o avanço da ciência e das tecnologias são parte dessa duplicidade de fins, tanto de preservação da vida como de sua destruição.

Compreendamos ou não os fenômenos e os objetos tecnológicos na sua complexidade, eles fazem parte de nosso dia-a-dia e afetam nossa capacidade de conhecer e de atuar na vida social. Há algum tempo atrás, Leonardo Boff (2004) publicou um instigante artigo que mostra dois lados complementares da vida humana no mundo atual, a importância da ciência e da tecnologia para o conhecimento do mundo em que vivemos e nossa relação íntima com a natureza, com o planeta Terra. ${ }^{2}$

Esse fato nos coloca diante de três exigências nos processos educacionais: primeiro, a científica, a proximidade com a ciência e a tecnologia, que nos permitem conhecer fatos como esse e manipular instrumentos que proporcionam conhecimentos e ações impensáveis para geraçōes passadas. Segundo, uma exigência ética, a interação do homem com a natureza está produzindo transformaçôes de alcance imprevisíveis e parece que está se rompendo gradativamente o equilíbrio interativo que permite a sobrevivência humana. Por último, a educacional, a formação humana de crianças, adolescentes e jovens para o mundo de hoje exige domínio de conhecimentos globais das ciências, das tecnologias e a socialização para uma convivência com o planeta e a humanidade, de modo a preservar a vida.

Com respeito ao tema específico deste texto, temos uma evidência que é a transformação dos CEFETs em instituições de ensino superior (Campello, 2005). A aprovação da Universidade Federal Tecnológica do Paraná é emblemática dessa decisão política. ${ }^{3}$ Temos algumas hipóteses para discussão e uma pergunta final. Pela primeira hipótese, consideramos que a transformação dos CEFETs em ensino superior é uma exigência posta por sua aproximação com o mundo da produção, da ciência e da tecnologia e a necessidade de formar para o trabalho complexo. ${ }^{4}$ 
Os Centros Federais de Educação Tecnológica e o ensino superior...

Uma segunda hipótese sobre essa transformação é a necessidade de formar professores para as disciplinas técnicas, considerando-se o número insuficiente formado pelas universidades nas suas licenciaturas plenas para suprir as necessidades do ensino médio técnico. Cabem aqui algumas perguntas. Por que as universidades formam um número insuficiente de professores? As licenciaturas oferecidas pelos CEFETs plenas ou breves? Quanto às breves, o que as distingue das licenciaturas plenas?

Pela terceira hipótese, a transformação dos CEFETs estaria expressando uma espécie de up grade ou de "diferenciação para cima", um dado reiterado na cultura brasileira, na forma de rejeição às atividades técnicas tradicionais consideradas subalternas. Esta tem uma origem histórica no mundo ocidental e no Brasil. Nossa herança é de quatro séculos de escravidão e cinco séculos de dualismo estrutural e discriminação étnica e social ante as atividades ditas manuais. ${ }^{5}$ No Brasil, todas as categorias de nível superior (ocupacionais, educacionais etc.) dão status e vantagens ao seu possuidor como se fossem, socialmente, mais relevantes, superiores às demais atividades. Exemplo disso é a busca desesperada da população por um título - não necessariamente o conhecimento - de nível superior.

Diante da evidência da transformação dos CEFETs em instituições de ensino superior ou em universidades, perguntamos, o que vai acontecer com o ensino médio? Vai se extinguir ou melhorar? E o PROEJA ${ }^{6}$ acordado com o MEC vai se tornar um ensino médio de qualidade para jovens e adultos trabalhadores, segundo a tradição das Escolas Técnicas Federais e dos CEFETs, ou vai se tornar um PLANFOR melhorado? ${ }^{7}$

Tendo como horizonte a necessidade de uma visão de totalidade social dos fenômenos, nas múltiplas relações que estabelecem, portanto, na sua complexidade, trataremos do tema proposto em sua dimensão histórica e política. Primeiro, refletimos sobre o significado da técnica e sua relação com o conhecimento, a ciência e as tecnologias. A seguir, trataremos brevemente dos termos cidadão produtivo e/ou emancipado e de uma breve visão do mundo econômico no qual se geram fenômenos desafiantes como a extrema desigualdade, a fome, o desamparo, a violência em todas as suas formas, tendo como contraponto sociedades ricas, complexas, de alto desenvolvimento científico e tecnológico. Em terceiro lugar, a questão da universidade, a produção do conhecimento e sua relação com o ensino médio e a formação de tecnólogos em nível superior. 
Diante da lógica da produção: a técnica e sua relação com a ciência e as tecnologias

Técnica, ciência e tecnologia são termos afins, provêm todos da relação fundamental estabelecida pelo ser humano com a natureza na preservação e reprodução da vida. Dois aspectos são imprescindíveis para a análise do tema: o trabalho e o contexto histórico ou a totalidade social na qual ocorrem a técnica, a ciência e as tecnologias. ${ }^{8}$

O trabalho no seu sentido ontológico, fundante da vida humana, criativo e humanizador está na gênese de todo conhecimento na produção dos bens necessários à sobrevivência, como os conhecemos na sociedade atual, os valores de uso. ${ }^{9}$

Mas, ao longo dos séculos, desenvolveram-se formas coletivas de produção e de organização social que transformaram o sentido e a apropriação dos valores de uso. $\mathrm{Na}$ sociedade capitalista, que já se estende ao longo de mais de dois séculos, os homens foram levados a vender sua força de trabalho, e os bens produzidos, apropriados pelos donos dos bens de produção, tornaram-se valores de troca, objeto de transações lucrativas no mercado. Geraram-se as condições de exploração do trabalhador e as formas de submissão a trabalhos aviltantes, tormentosos, esvaziados de seu poder criador.

O avanço científico tecnológico nos processos produtivos e as atuais formas de organização do trabalho deram ensejo a novas interpretaçôes para as transformações em curso. Enfatiza-se hoje a importância da educação para a "sociedade do conhecimento". O que significa? Quais são elas? Será o Brasil uma "sociedade do conhecimento?".

A partir da terceira revolução industrial ou a revolução das novas tecnologias que são, essencialmente, tecnologias intelectuais, forjaram-se "as bases de uma economia do conhecimento, colocando-o no cerne da natureza humana, do desenvolvimento e das transformaçôes sociais". Mas as informaçōes que circulam não são, necessariamente, conhecimento, e os conhecimentos que deveriam ser compartilhados são prejudicados pela competitividade e pelas crescentes divisões existentes entre as sociedades e no interior delas. Além disso, aumenta progressivamente a distância entre os países na produção, no acesso e na apropriação da ciência e das tecnologias. Alguns países vêm investindo maciçamente em educação e em pesquisa científica há várias décadas, elevando o nível de vida da população e de produção do conhecimento (Matsura, 2005). 
Os Centros Federais de Educação Tecnológica e o ensino superior...

Esse processo tem uma história antiga. Losano (1992) mostra que o domínio sobre a natureza, desenvolvido a partir da mecânica racional e da expansão das capacidades técnicas do ser humano, precedeu o amadurecimento das tecnologias. Mas "esse domínio era mais conhecimento do que uso", estava ligado ao saber, não à produção. Foi com a revolução industrial que as máquinas, criadas do século XVI ao século XVIII, passaram a ser usadas no século XIX como bens úteis, isto é, para produzir bens econômicos, mercadorias que circulam como valores de troca. É quando a atenção dos estudiosos vai se concentrar no motor primário - a vapor, de explosão ou elétrico. E aí "nasce a tentação de reproduzir a natureza por meios mecânicos". Hoje, já não se trata apenas de reproduzir cada uma das ações humanas por meios mecânicos e, sim, de que "a máquina realize uma única ação, mas substituindo mil homens". Com o tempo, o mundo da mecânica veio a ser superado pela eletrônica e pela informática (p. 113-122, grifos do autor).

O pesquisador espanhol Carlos Paris (2002) pergunta se a abundância da técnica no mundo atual propicia que nos libertemos do reino inferior da necessidade, para podermos então encontrar a nós mesmos, em nossa autenticidade de gênero humano. Argumenta que a história da apropriação da técnica e das tecnologias revela que seu uso não se destinou a facilitar a todos a fruição do mundo da liberdade, da criação da arte e do conhecimento. O que vemos é "a captação da técnica como um poder [que] abre um mundo decisivo de experiências antropológicas", até mesmo, a mais inquietante delas, a técnica contra o próprio homem, "um poder que nos esmaga e desumaniza, que póe, inclusive, em risco a sobrevivência física da humanidade, de uma grande parte da vida sobre o planeta" (p. 151-157).

Mas não apenas esse risco extremo nos ameaça. Trata-se também da desumanização promovida pelo poderio tecnológico. A técnica, tanto a tecnológica como a burocrática e centralizadora de interesses, domina se autonomizando, auto-alimentando-se em benefício dos próprios processos que são os da atividade produtiva (ibid., p. 158). Não se nega a importância do desenvolvimento das forças produtivas, mas, sim, sua insuficiência para a emancipação humana. $\mathrm{O}$ que significa isso em termos de conhecimento e em relação à educação tecnológica em nível de ensino superior?

Paris fala do "império da tecnocracia, um poder fundamentalmente gestor da lógica interna que o próprio desenvolvimento tecnológico impli- 
ca”, na medida em que este não é apenas o aperfeiçoamento da técnica, mas a aplicação da ciência e da técnica a serviço da produção capitalista cuja lei fundamental é a reprodução ampliada do capital. Tudo mais é acessório, não obstante todos os discursos em contrário (a natureza, o ser humano, a vida, o planeta). A imagem da técnica como alienação do homem do produto de seu trabalho, de si mesmo e dos outros homens, pode ser vista no seu potencial de dominação, esmagador do ser humano, inclusive, na sua relação com o conhecimento (ibid., p. 161-162). ${ }^{10}$

O saber técnico, seu poder de sedução e de dominação por meio da produção está na origem do nascimento da ciência moderna e do avanço que representou, na história da humanidade, a passagem do centro do universo da terra para o sol, da verdade divina para a verdade estabelecida pelo ser humano. Mas, desde o início, a contradição se fez presente na concepção dos fenômenos como se pudessem ser conhecidos como partes separadas, independentes do todo que as articula, e não uma unidade vital, um mundo inter-relacionado nos seus múltiplos aspectos. Desvincular a técnica, a ciência e as tecnologias de seu contexto, do universo de relações sociais e de classe que elas estabelecem é o caminho do determinismo tecnológico (Frigotto, 2005, p. 3) que opera por uma "descontextualização da tecnologia" ao tratá-la como força autônoma desvinculada das ações humanas que a produziram e dela se apropriaram em contextos históricos (Lima Filho, 2005, p. 5).

"O sistema de pensamento voltado para o mundo em sua totalidade foi desafiado pelos resultados apresentados pela ciência experimental (...) e a racionalidade dos conteúdos passou a depender somente da racionalidade dos procedimentos" (Hilst, 1994, p. 64). A ciência experimental se constituiu confiando em seus próprios procedimentos, no método científico. O método se tornou referência de si mesmo e não o ser humano com seus fins éticos, morais, estéticos, físicos e espirituais, não mecânicos, não técnicos, não apenas produtivos, abstraídos, separados da própria condição humana.

Como tudo que é criado pelo ser humano é apropriado para suprir suas necessidades, o saber se torna pragmático, funcional a quem detém a propriedade dos meios de produção, aos grupos constituídos em torno à rentabilidade do capital. Muitas são as mediações que viabilizam esse processo açambarcante (a produção da terra, o domínio dos minerais, das águas, dos mares e todas as suas plantas e animais, os produtos do engenho humano, a arte e o conhecimento). 
Os Centros Federais de Educação Tecnológica e o ensino superior...

Oliveira (2005) discute a ciência como força produtiva, como mercadoria no sistema capitalista. Particularmente, nas duas últimas décadas neoliberais, valorizam-se as aplicaçóes da ciência, sua capacidade de gerar tecnologias, em detrimento do conhecimento como um fim em favor da vida humana. Houve "um processo de tecnologização da ciência, do qual um dos reflexos é o neologismo 'tecnociência"”. O novo termo em uso é o inglês commodisation ou a mercantilização da ciência que significa utilizá-la como mercadoria, assim como a mercantilização das tecnologias "como parte de um processo mais amplo de mercantilização dos bens intelectuais" (p. 81 e 84, grifos do autor). ${ }^{11}$

Para fins de nossa reflexão, importa, particularmente, a contradição entre essa lógica que é a lógica da produção capitalista e a lógica da educação. A primeira tem base no lucro, na exploração do trabalho, no tempo breve em que deve se realizar a atividade produtiva, no corte de custos, no aumento da produtividade do trabalho, na competitividade, na mercantilização de toda produção humana. A segunda, por ter a finalidade de formar o ser humano, deve pautar-se pela socialização do conhecimento, o diálogo, a discussão, o tempo médio e longo da aprendizagem, a humanização, a emancipação das amarras da opressão, o reconhecimento das necessidades do outro, o respeito à sua individualidade, a participação construtiva e a cidadania. Em resumo, esta é a questão de fundo, o desafio que está posto quando falamos sobre a atividade formativa dos CEFETs, tanto no ensino médio técnico e profissional, como no ensino superior.

Diante da lógica da educação: educar o cidadão produtivo ou o cidadão emancipado? ${ }^{12}$

Não é uma tarefa simples pensar em pessoas educadas para serem emancipadas, diante da dupla dominação em que nos movemos no Brasil: a da sociedade de mercado e sua nova linguagem, e a dominação historicamente construída em torno do conceito de cidadão. A sociedade de mercado implanta-se entre nós na condição de país capitalista dependente. A teoria da dependência que nasceu no âmbito da Comissão Econômica para a América Latina (CEPAL), nos anos de 1950, já foi extensamente revista nas suas premissas e no seu desvio para a interdependência segundo a análise de Cardoso e Faletto (1979). A idéia da dependência foi banida do vocabulário econômico-político pela sua oposição crítica. 
Mas o fenômeno em si, do capitalismo dependente permanece e sua análise crítica foi resgatada por outros autores (Bambirra, 1983; Marini, 2000; Santos, 1998; Cardoso, 2005).

Desde a Colônia, o capitalismo se desenvolve na América Latina "em estreita consonância com a dinâmica do capitalismo internacional". $\mathrm{Na}$ Colônia, como produtora de metais preciosos e bens exóticos, contribuindo para o desenvolvimento do capital comercial e bancário na Europa. Depois da Independência, no século XIX, produzindo e exportando bens primários em troca de manufaturas de consumo. Iniciam-se então os déficits comerciais e os empréstimos externos para sustentar a capacidade de importação. Toma forma o aumento da dívida externa. ${ }^{13}$

É a partir desse momento que se configura a dependência, entendida como uma subordinação entre naçôes formalmente independentes, em cujo âmbito as relações de produção das naçōes subordinadas são modificadas ou recriadas para assegurar a reprodução ampliada da dependência. (Marini, op.cit., p. 107-109)

Neste fenômeno fundamental está uma das barreiras a uma política de desenvolvimento científico-tecnológico e de educação ampliada para a ciência e as tecnologias. É o que demonstra a declaração do ex-Ministro da Educação Paulo Renato de Souza à Revista Exame no início de seu governo, quando considera que, com a globalização, o acesso ao conhecimento ficaria facilitado pelas empresas a países como o Brasil. ${ }^{14}$

A dominação histórica dos centros hegemônicos ocorre também por meio da linguagem, dos novos termos que se difundem como uma nova língua, cuja influência é amplificada pelos meios de comunicação. Chama a atenção o fato de que as mudanças sociais que vivemos a partir das últimas décadas do século XX trazem, de forma insistente, um conjunto de vocábulos ou noçōes que, no entender de Bourdieu e Wacquant (2001), constituem uma espécie de "nova língua". Esses autores fazem uma síntese ampla desta nova vulgata no contexto da nova (des)ordem mundial decorrente da mundialização do capital, da ideologia neoliberal e do pós-modernismo.

Segundo os autores, "Em todos os países avançados, patróes, altos funcionários internacionais, intelectuais de projeção na mídia e jornalistas de primeiro escalão se puseram em acordo em falar uma estranha novlangue" repetida à exaustão pelos meios de comunicação: 
Os Centros Federais de Educação Tecnológica e o ensino superior...

globalização, flexibilidade, governabilidade, empregabilidade, underclass e exclusão, nova economia, tolerância zero, comunitarismo, multiculturalismo, etnicidade, identidade, fragmentação etc. Mas estão ausentes palavras como capitalismo, classe, exploração, dominação, desigualdade, que revelariam a materialidade da dominação $(2001$, p. 1).

Poderosas redes mundiais controladas por forças conservadoras divulgam o ideário do mercado: ajuste estrutural, austeridade, corte de gastos públicos, superávit primário, privatização, abertura comercial, eficiência, produtividade, garantia aos investidores, enxugamento, terceirização, flexibilização de direitos, demissões voluntárias (idem, ibid.). No campo educacional, esse decálogo se expressa com os vocábulos de qualidade total, sociedade do conhecimento, educar por competência e para a competitividade, empregabilidade, cidadão ou trabalhador produtivo etc.

A luta da classe trabalhadora e de seus intelectuais ao longo de dois séculos do capitalismo, foi buscar, sistematicamente, não só desmascarar o falseamento das noçōes de produtividade e de trabalhador produtivo, mas lograr conquistas importantes em termos de regulamentação do capital e de pôr freios à superexploração do trabalho. $\mathrm{O}$ trabalhador brasileiro é um cidadão em luta permanente por essa emancipação fundamental.

Há no conceito de trabalhador produtivo uma dificuldade adicional à semântica que advém do valor que se acrescenta a qualquer produto do trabalho assalariado. No seu sentido próprio, produtivo é quem produz algo, produz bem, produz com qualidade. Se esse produto é apropriado por quem detém os meios de produção, à exigência do produto ser o que deve ser como tal, acrescenta-se um valor excedente, o valor de troca que não reverte para o trabalhador, mas para o dono da produção.

Toda organização do trabalho, toda implementação da produção com novas tecnologias, todas as contenções salariais concorrem para o aumento da produtividade neste segundo sentido, tornando o produto mais rentável, mais competitivo. Marx diz singelamente: "um mestreescola é um trabalhador produtivo quando trabalha não só para desenvolver a mente das crianças, mas também para enriquecer o dono da escola. Que este inverta seu capital numa fábrica de ensinar em vez de uma fábrica de salsicha, em nada modifica a situação" (Marx, 1980, p. 584). ${ }^{15}$ Quando falamos em formar o cidadão produtivo, a qual rela- 
ção de trabalho nos referimos: a que cria valores de uso apenas ou a que adquire um valor de mercado? Qual é o papel da escola, dos CEFETs?

Por sua vez, a utilização do termo cidadania também guarda ambigüidade, embora seu uso seja lugar-comum nas reflexões que tratam das questóes educacionais, principalmente a partir do final dos anos de 1970. É quando o país ressurge dos anos da ditadura para um movimento amplo de luta pelos direitos, de afirmação dos direitos da cidadania para todos os brasileiros.

Mas a própria questão da cidadania é, originalmente, uma questão alheia à constituição da sociedade brasileira pós-colonial, situação que teria se prolongado sob o fenômeno da exclusão dos "cidadãos" brasileiros de diversas instâncias da vida social. A questão ainda atual, que lhe está subjacente, é quem pertence à comunidade política e, por extensão, quem são os cidadãos e quais são os seus direitos de brasileiros?

É preciso remontar brevemente à história do nascimento da nação brasileira após a ruptura com o império colonial. Para Santos (1978, p. 78-80), os anos de 1822 a 1841 foram cruciais para a definição do tipo de sociedade que seria o Brasil. Para os liberais que conspiraram contra o regime colonial, o poder imperial deveria ser diminuído e a sociedade brasileira deveria governar o país. O que significava responder a várias questōes: de onde emanava a fonte do poder político legítimo, se este deveria repousar sobre o centro de poder ou se o poder deveria ser delegado mediante mecanismos de representação política e social, e quem estava qualificado para estas funçôes, quem pertencia à comunidade política como cidadão político pleno e para que servia o governo e o Estado.

O pacto constitucional apoiado pela elite brasileira estabeleceu que o poder imperial antecedia a criação da sociedade. Nenhum dos poderes da comunidade política, o Legislativo, o Judiciário e o Executivo, poderia ultrapassar o poder imperial, cuja função era "o canal adequado para exprimir a vontade do povo". O Imperador era o Poder Moderador e todos os ministros respondiam perante ele e não perante a comunidade política.

A constituição de 1824 inaugurava a nação brasileira e considerava todos os homens cidadãos livres e iguais, também garantia a todos o direito de propriedade, inclusive o direito de ter escravos. Este seria outro grande limite do pensamento liberal e sobre quem pertencia à comunidade política (Mattos, 2000). Esses aspectos da fundação da nação brasileira, ainda hoje, são familiares por meio da desigualdade es- 
Os Centros Federais de Educação Tecnológica e o ensino superior...

trutural da sociedade de classes e da distribuição da riqueza social. Aos mais pobres e miseráveis destinam-se os parcos serviços sociais deteriorados, as políticas assistencialistas e o voto nos representantes políticos.

O que significa educar o cidadão emancipado e não apenas o cidadão produtivo? Ser produtivo, buscar a produtividade do trabalho e a qualidade dos produtos é, em si mesma, uma coisa boa, uma busca da humanidade em todas as épocas e ainda hoje, até no mais simples artesanato. Mas como redirecionar a formação do cidadão produtivo subsumido pelos critérios mercantis da produção capitalista? Como superar a dualidade estrutural da sociedade brasileira que sempre destinou o ensino médio propedêutico ao que se destinam ao ensino superior, à formação da intelectualidade; e o ensino profissional aos "desfavorecidos da fortuna", aos filhos de trabalhadores, herdeiros das funçôes subalternas e das atividades manuais? ${ }^{16}$

Não há receitas para ordenar a vida social, mas há preceitos educacionais que as escolas conhecem e, por isso, sabem como devem ser preparados os jovens e os adolescentes para uma ou outra destinação. A qualidade das escolas, a formação dos professores e, principalmente, a organização curricular respondem por uma educação fragmentada entre o geral e o específico, entre o conceito e a prática, entre a fundamentação científica da produção e da tecnologia, e o aprendizado operacional pautado pela lógica estrita da produtividade. Esta se desdobra na naturalização dos conceitos e na aceitação das noçóes apropriadas segundo os interesses do mercado (empregabilidade, ajuste estrutural, flexibilidade etc.) em que se prepara a aceitação da sociabilidade capitalista, de sua disciplina e expropriação dos meios de vida da maioria dos trabalhadores desempregados, subempregados, precarizados de toda sorte.

A discussão sobre a formação do cidadão produtivo, no sentido de colocar a educação profissional e técnica de nível médio a serviço do mercado, como determinou o Decreto n. 2.208/97, ensejou a possibilidade de recuperação da dimensão humanística com sua revogação por meio do Decreto n. 5.154/2004, quando autoriza a volta do ensino integrado. $\mathrm{O}$ que significa remeter a educação técnica de nível médio a seus fundamentos científico-tecnológicos e histórico-sociais, à compreensão das partes no todo a que pertencem, de tratar a educação como uma totalidade social, isto é, suas múltiplas mediaçōes históricas e não apenas as técnicas, tecnológicas ou produtivas. 
No caso da formação integrada ou do ensino médio integrado ao ensino técnico, queremos que a educação geral se torne parte inseparável da educação profissional em todos os campos nos quais se dá a preparação para o trabalho: seja nos processos produtivos, seja nos processos educativos como a formação inicial, como o ensino técnico, tecnológico ou superior (Ciavatta, 2005). Significa que buscamos enfocar o trabalho como princípio educativo, no sentido de superar a dicotomia trabalho manual/trabalho intelectual, de incorporar a dimensão intelectual ao trabalho produtivo, de formar trabalhadores capazes de atuar como dirigentes e cidadãos (Gramsci, 1981, p. 144 e ss.).

O tema da formação integrada coloca em pauta uma concepção de educação que está em disputa permanente na história da educação brasileira: Educar a todos ou a uma minoria, supostamente mais apta ao conhecimento? A uns e a outros que tipo de educação deve ser dada de modo a atender às necessidades da sociedade e não apenas à reprodução do capital?

Pela concepção de formação integrada deve-se superar o ser humano dividido historicamente pela divisão social do trabalho entre a ação de executar e a ação de pensar, dirigir ou planejar. Trata-se de ir além da preparação para o trabalho reduzida ao seu aspecto operacional, simplificado, escoimado dos conhecimentos que estão na sua gênese científicotecnológica e na sua apropriação histórico-social. Como formação humana, o que se busca é garantir ao adolescente, ao jovem e ao adulto trabalhador o direito a uma formação completa para a leitura do mundo e para a atuação como cidadão pertencente a um país, integrado dignamente à sua sociedade política. Formação que, neste sentido, supõe a compreensão das relaçóes sociais subjacentes a todos o $s$ fenômenos (Ciavatta, 2005).

Discutindo a idéia de progresso, à luz da historicidade do conhecimento e do valor relativo do pensamento dos clássicos à época em que foram produzidos, o historiador Paolo Rossi (2000, p. 15) assim se expressa:

(...) nenhum expoente da Revolução Científica jamais afirmou que a libertação do homem pudesse ser confiada à ciência e à técnica enquanto tais: a restauração do poder humano sobre a natureza, o avanço do saber só têm valor se realizados num contexto mais amplo que concerne - em conjunto e simultaneamente - à religiăo, à moral, à política. 
Os Centros Federais de Educação Tecnológica e o ensino superior...

Em outros termos, significa que a emancipação humana se faz na totalidade das relações sociais nas quais a vida é produzida.

CEFET, ensino superior e universidade tecnológica: a opção pelo modelo empresarial na atividade educativa?

Nesta última seção queremos refletir sobre o significado da transformação em curso dos CEFETs em instituições de ensino superior, inclusive, em universidades tecnológicas. Em recente entrevista o ex-reitor da UFRJ, Carlos Lessa (2005), lembrava que "a universidade não é o andaime da educação nacional e, sim, o seu alicerce. É o espaço de reposição das geraçôes nacionais (...). Os impérios sempre bloquearam o ensino superior nas colônias".

Sabemos que a soberania dos países não advém apenas da posse de armas para defender seu território, mas também da autonomia para produzir conhecimento e responder às demandas de vida de seu povo. Assim, entende-se por que a educação se coloca como uma questão estratégica, no nível básico para a educação fundamental e média de crianças e adolescentes, e no nível superior para o aperfeiçoamento profissional, científico e tecnológico de jovens e adultos e para a produção do conhecimento que assegura a presença de um país entre as demais naçóes. Esta compreensão não é constituída de elementos autônomos, isolados, mas profundamente imbricados uns em outros, enraizados no tecido social e disseminados pela palavra, pelos discursos que construímos no entendimento e nas ações (Ciavatta, 2003).

Pensar a ciência e o desenvolvimento científico-tecnológico no contexto da realidade social e econômica em que vivemos, significa pensar o conhecimento na história da produção social da existência humana, nas suas diversas temporalidades. Implica localizar, datar, buscar limites, relações explícitas e implícitas, entender os acontecimentos e suas transformaçōes. Significa estar atento não apenas às relaçōes de causa e efeito, variáveis, fatores, tão ao gosto das ciências matemáticas e da natureza, mas às mediaçōes e contradições articuladas em totalidades sociais, como partes de um contexto que dá sentido e significado ao conhecimento, e evidencia as formas de seu uso e apropriação.

Esta última é uma linguagem e uma visão de ciência fora de moda diante da negação das categorias ontológicas, do relativismo e do ceticis- 
mo instrumental. Nem "o certificado de cientificidade, de corte positivista" que legitimava as ciências por sua suposta objetividade, isenção, neutralidade, ausência de preconceitos e suposições, não mantém o mesmo valor simbólico.

É certo que permanece a busca dos procedimentos mais adequados e confiáveis para passar dos "fatos" aos "dados", às teorias a aos modelos. Mas circula com desenvoltura nos meios acadêmicos a desilusão com o saber científico e sua contribuição ao progresso da humanidade:

(...) programas de pesquisa científica, jogos de linguagem, phrase régimes, formas de vida, esquemas conceituais, entre outros, caracterizam uma variedade de doutrinas, não obstante suas diferenças, convergem em um ponto fundamental: a defesa do relativismo ontológico. (Duayer, 2003, p. 1-2)

No âmbito da produção do conhecimento nas universidades e instituições de pesquisa, estamos diante de duas questôes, aparentemente, em oposição: as novas filosofias relativistas e o produtivismo acadêmicocientífico, a ciência como "métrica do conhecimento". O rigor científico e metodológico e a pesquisa como força produtiva, que alimentam o extraordinário desenvolvimento científico e tecnológico que nos envolve, são pautas indispensáveis à sustentação dos novos conhecimentos e à sua utilização na produção mercantilizada em escala global, com dividendos de poder e financeiros quase ilimitados. Esse processo conduz os países ricos a uma incessante competição pelas idéias, pelos novos materiais, pela biodiversidade, pela disputa de cérebros e pela corrida armamentista. Paralelamente, o mesmo ideário é repassado aos países da periferia do núcleo orgânico do capital e introduz modelos estranhos à nossa realidade, reorganizando autoritariamente os modelos educativos, impondo escalas comparativas incompatíveis com as necessidades locais e com suas condições de produção do conhecimento.

Quando os CEFETs se tornam instituições de ensino superior e almejam ser universidades tecnológicas ou já o são, quais as referências teóricas com que abordam a questão da produção do conhecimento, da relação técnica, ciência e tecnologias? Como as articulam com a educação de jovens estudantes? Como analisam o produtivismo que preside o modelo de avaliação do ensino superior, da pós-graduação? 
Os Centros Federais de Educação Tecnológica e o ensino superior...

A universidade brasileira, desde sua implantação, combinou o ideário da universidade de pesquisa de Von Humboldt, a pesquisa básica, o saber não imediatamente interessado, e a universidade napoleônica, o modelo francês profissionalizante. Dupla orientação que pode representar uma dificuldade de ordem prática, uma vez que exige dos docentes as atividades de ensino e pesquisa e, mais recentemente, a extensão que pode ser um pleonasmo se considerarmos que o ensino é, por excelência, a atividade de extensão às comunidades por meio da formação de seus profissionais.

Mas essa dupla orientação constitui uma resposta adequada a um país que, diferentemente dos demais países da América Latina e, principalmente, dos europeus, construiu tardiamente seu sistema universitário, abrindo-se para as diversas áreas do conhecimento, para o cultivo do saber institucionalizado sobre os múltiplos aspectos e problemas da vida no planeta. A exigência da lei de um número de cursos para uma instituição se tornar uma universidade não é mera formalidade, é o reconhecimento da complexidade das ciências matemáticas, da natureza e das ciências humanas e dos fenômenos sociais. Sua separação não corresponde à realidade dos fenômenos da natureza e sociais que vivenciamos como um todo indivisível no nosso dia a dia - dado pela unidade de consciência dos sujeitos que conhecem e pela totalidade histórica que os constitui. Sua separação para fins científicos e acadêmicos é fruto da complexidade progressiva das diversas áreas e disciplinas que se tornam autônomas e poderosas de acordo com sua especialidade, buscando salvaguardar seu prestígio e recursos para o ensino e a pesquisa.

Quando se fala em universidade tecnológica, o que significa? Embora o termo universidade tecnológica seja de uso comum também em outros países, não deixa de ser uma contradição em termos. Mas a questão terminológica não é o fundamental nesta discussão. A questão básica é que tipo de pesquisa as universidades tecnológicas vão fazer ou estão fazendo, porque elas são, também, instituições formativas. Destinam-se apenas ao desenvolvimento de tecnologias para o mundo produtivo? $\mathrm{Ou}$ incluem em seus programas e projetos de investigação a apropriação histórico-social do conhecimento? Consideram e deslindam junto a seus estudantes a situação do ser humano sob o domínio da técnica e do complexo industrial-militar que fomenta e alimenta as guerras e a destruição para renovar os ciclos da reprodução do capital? Qual é sua referência teórico-prática, a lógica da produçẫo ou a lógica da educação? 
Outra questão correlata a esta é a formação de nível médio e de tecnólogos. A LDB não garante educação obrigatória gratuita de nível médio. ${ }^{17}$ Os CEFETs, as Escolas Agrícolas Federais, o Colégio Pedro II e os Colégios de Aplicação das universidades federais são as poucas instituições públicas de qualidade a oferecer esse nível de ensino, considerando que a maior parte dos estados brasileiros têm seus sistemas de escolas de nível médio em condiçōes deficitárias. São dois os problemas em perspectiva. Primeiro, uma vez que as escolas técnicas se tornem CEFETs e passem a oferecer ensino superior de tecnólogos, de graduação e de pós-graduação, haverá espaço e disponibilidade docente para atuar no ensino médio? Segundo, a formação de tecnólogos em nível superior, os cursos breves (comparados aos cursos de quatro anos ou mais das universidades), incluem a pesquisa ampliada, com base nos fundamentos da ciência ou prevalecem os objetivos operacionais para o mercado? Essa pergunta parece retórica se pensarmos que o Decreto n. $87.310 / 82$

(...) ao definir as características básicas dos Centros Federais de Educação Tecnológica, limita sua atuação exclusivamente à área tecnológica e determina que desenvolvam o "ensino superior como continuidade do ensino técnico de $2^{\circ}$ grau e diferenciado do sistema de ensino universitário" (art. $3^{\circ}$ ). Esse decreto, portanto, corrige a Lei n. 6.545/78 e direciona a atuação dessas instituiçôes para a formação de tecnólogos, carreiras curtas criadas na fragmentação do ensino superior. (Campello, 2005, p. 73)

Há aí, claramente, um direcionamento funcional para o conhecimento tecnológico próprio ao campo da ciência aplicada à produção. Ela deixa de ser apenas retórica se pensarmos que um país não deveria subsumir a vida intelectual de uma instituição a objetivo tão limitado. Ou se pensarmos em um projeto nacional subordinado que se antecipa em mais de uma década ao pensamento do Ministro da Educação em 1996, apoiando-se no acesso ao conhecimento que seria facilitado pela globalização. Ou se pensarmos na disputa de mercado para os CEFETs, de modo a não se sobrepor às mesmas funções das universidades.

Uma última questão diz respeito à decisão do governo federal quanto à oferta de, no mínimo, 10\% de suas vagas oferecidas em 2005 pelos Cefets para o Programa de Educação Profissional Integrada ao 
Os Centros Federais de Educação Tecnológica e o ensino superior...

Ensino Médio na Modalidade de Educação de Jovens e Adultos (PROEjA) (Brasil, 2005b), destinado a jovens acima de 18 anos e adultos que tenham cursado apenas o ensino fundamental. Apresenta-se como objetivo desse programa, a ampliação dos espaços públicos da educação profissional para os adultos e uma estratégia que contribui para a universalização da educação básica. ${ }^{18}$

Vale observar que as instituições federais, individualmente, salvo algumas poucas exceções, ou como rede, não fizeram qualquer movimento significativo, no sentido de integrar os ensinos médio e técnico. Ademais, com o reconhecimento dos Centros Federais de Educação Tecnológica (CEFETs) como instituições de ensino superior, ${ }^{19}$ a prioridade tenderá a ser conferida à oferta da educação superior em detrimento do nível médio. ${ }^{20}$

\section{Considerações finais}

Escolas técnicas federais em um primeiro momento, os Centros Federais de Educação Tecnológica constituem uma reserva de educação de qualidade no país. O Brasil não demonstrou ainda ter um projeto efetivo de escolarização básica universalizada para toda a população, gratuita e de qualidade. Não é por acaso que os organismos internacionais, que monitoram a redução de gastos públicos e o pagamento das dívidas interna e externa, induziram a reforma educacional implementada por meio do Decreto n. 2.208/97, a Portaria MEC n. 646/97, além de outros instrumentos legais, juntamente com a oferta dos recursos do PROEP. É recorrente, nessa intervenção consentida pelas autoridades brasileiras, a censura, nessas instituiçóes, ao atendimento a alunos das classes médias que, supostamente, deveriam ir para o setor privado - recomendação que não se aplica aos países centrais do capitalismo que asseguram educação básica para sua infância e juventude, inclusive aumentando o número de anos de escolaridade obrigatória.

Voltando a nossas hipóteses iniciais para o debate, qual o significado das transformaçôes em curso? Temos uma evidência que é a transformação dos CEFETs em instituições de ensino superior. Por nossa primeira hipótese, consideramos que a transformação dos CEFETs em ensino superior é uma exigência posta por sua aproximação com o mundo da produção, da ciência e da tecnologia. As análises sobre o tema mostram 
as ambigüidades de fins das tecnologias hoje e as contradições que estão postas pelo que representam como avanço do conhecimento, utilizado amplamente para a destruição. Defendemos que os CEFETs, como escolas públicas de qualidade, devem submeter à análise crítica a relação que estabelecem com a técnica, a ciência e as tecnologias em um país de capitalismo periférico dependente dos países centrais.

Pela segunda hipótese, estaria subjacente à transformação dos CEFETs a necessidade de professores para as disciplinas profissionais, não atendida suficientemente pelas universidades. No entanto, se a formação oferecida pelos CEFETs se pautar pela oferta de cursos breves, pela redução da formação às questôes tecnológicas demandadas pelo mercado, pela lógica do mercado, esses professores estarão sendo lesados mesmo que com seu consentimento - no direito a uma formação condizente com a lógica da educação e da humanização daqueles jovens e adultos que lhes serão confiados.

Pela terceira hipótese, a transformação dos CEFETs em instituições de ensino superior expressaria, em parte, a rejeição às atividades técnicas, supostamente, subalternas, que tem uma origem histórica no mundo ocidental e no Brasil, com seus quatro séculos de escravidão e cinco de dualismo estrutural e discriminação étnica e social ante as atividades manuais. Em um mundo saturado de alta tecnologia, apropriação privada da riqueza social e o empobrecimento crescente de grandes massas da população, como os CEFETs se aproximam dessa questão? Qual a leitura do mundo para o qual preparam seus alunos?

Destinados, originariamente, para as "classes desfavorecidas", que continuam a procurá-los pelo vínculo da escola com o trabalho, a questão das classes sociais e a exclusão de tantos dos benefícios sociais são aspectos da realidade que não podem ser alheios à sua prática pedagógica. A técnica não é uma questão técnica, é uma questão política no sentido de que surge, é criada para dar solução a problemas humanos e sofre todas as distorções da apropriação privada em favor de classes e grupos sociais hegemônicos. As armas poderosas das intervenções militares, os alimentos transgênicos, a indústria farmacêutica, são alguns exemplos da mercantilização do conhecimento em favor dos países ricos, com graves conseqüências para os mais pobres. Estas questões são inerentes à ação educativa profissional e técnica, seja nos atuais CEFETs, seja nas futuras universidades tecnológicas. 
Os Centros Federais de Educação Tecnológica e o ensino superior...

\section{Recebido em julho de 2006 e aprovado em agosto de 2006.}

\section{Notas}

1. Em palestra proferida no Centro Federal de Educação Tecnológica do Rio de Janeiro, em 6 out. 2005 .

2. Dizia ele que a Terra possui um campo magnético de 7,83 ondas hertz por segundo que é responsável pelo equilíbrio da biosfera, condição comum a todas as formas de vida (fenômeno que leva o nome de ressonância Schumann). Todos os vertebrados e o cérebro humano são dotados da mesma freqüência, 7,83 hertz. A partir dos anos 1980 e, de modo acentuado, nos anos 1990, a freqüência passou de 7,83 para 11 e para 13 hertz. Fizeramse sentir desequilíbrios ecológicos, perturbaçōes climáticas, maior atividade dos vulcōes, crescimento das tensōes e conflitos. Há uma aceleração do tempo (movimento no espaço) de modo que a jornada de 24 horas é de apenas 16 horas ou é vivida como se assim fosse. Sua análise pondera que Terra é um superorganismo vivo e a humanidade forma com ela uma unidade (Boff, 2004).

3. Lei n. 11.184, de 7 de outubro de 2005 .

4. "Trabalho humano mede-se pelo dispêndio da força de trabalho simples, a qual, em média, todo homem comum, sem educação especial, possui em seu organismo. O trabalho simples médio muda de caráter com os países e estágios da civilização, mas é dado numa determinada sociedade. Trabalho complexo ou qualificado vale como trabalho simples potenciado ou, antes, multiplicado, dado que uma determinada quantidade de trabalho qualificado é igual a uma quantidade maior de trabalho simples" (Marx, 1980, p. 51, grifos do autor).

5. Não vamos nos deter na unidade mão e cérebro, suficientemente demonstrada pela ciência atual.

6. Programa de Integração da Educação Profissional Integrada ao Ensino Médio na Modalidade de Educação de Jovens e Adultos, Decreto n. 5.478, de 24 de junho de 2005.

7. A avaliação dos cursos oferecidos pelo PLANFOR mostrou muitos deles com cargas reduzidas, insuficientes mesmo para uma formação inicial, ofertas desarticuladas das demandas locais, inexistência de articulação com a elevação de escolaridade (ver, entre outros, Ciavatta, 2000; Ventura, 2001; Santos, 2003).

8. Em sua análise, Lima Filho (2005), além desses aspectos, destaca a polissemia do conceito de tecnologia, as narrativas tecnológicas, o determinismo tecnológico e sua historicidade. Frigotto (2005) destaca as contradiçôes, antagonismos e conflitos que ocorrem em meio às lutas de classe, a técnica como força de dominação e de alienação, a divisão social do trabalho e o capitalismo dependente associado em um país periférico ao capitalismo central, como ocorre no Brasil.

9. "O trabalho, como criador de valores de uso, como trabalho útil, é indispensável à existência do homem - quaisquer que sejam as formas de sociedade -, é necessidade natural e eterna de efetivar o intercâmbio material entre o homem e a natureza e, portanto, de manter a vida humana" (Marx, 1980, p. 50).

10. É antiga na história da humanidade a tensão entre o ser humano e o conhecimento que ele mesmo produz. Ela se revela no livro sagrado dos maias, ao relatar a rebelião dos instrumentos contra os seres humanos (Paris, op. cit., p. 163). 
11. "Bens intelectuais são idéias, num sentido amplo, que inclui conhecimentos de vários tipos: descobertas, invenções, criações artísticas, enfim, todas as entidades abstratas criadas pela mente humana. De outro ponto de vista, os bens intelectuais incluem bens protegidos pelos direitos de propriedade intelectual, que por sua vez incluem as patentes, os direitos autorais, as marcas e os segredos comerciais" (Oliveira, op. cit., p. 84, grifos do autor).

12. Algumas reflexões desta seção têm base em Frigotto e Ciavatta, 2003.

13. "Entre 1902-1913, enquanto o valor das exportações aumenta em 79,6\%, a dívida externa o faz em 144,6\% e representa, em 1913, 60\% do gasto público total” (Barboza-Carneiro, J.A., apud Marini, 2000, p. 109). A título de exemplo, sobre o agravamento dessa assimetria ao longo do século XX, dados do FMI mostram que, no período 1990-1997. enquanto em países do núcleo orgânico do capital, como os Estados Unidos, o aumento nas exportações foi de $74,7 \%$ e, nas importações, de $76,1 \%$; e na União Européia foi $38,3 \%$ e $27,2 \%$, respectivamente; no Brasil, foi de 68,8\% e 188,6\%; e na América Latina, $84,3 \%$ e $160,8 \%$ (Sader, 2001, p. 90)

14. Exame, São Paulo, ano 30, n. 15, p. 4, 17 jul. 1996.

15. Ainda sobre trabalho produtivo, ver Marini (2000), entre outros.

16. "Considerando: que o aumento constante da população das cidades exige que se facilite às classes proletárias os meios de vencer as dificuldades sempre crescentes da luta pela existência; que para isso se torna necessário, não só habilitar os filhos dos desfavorecidos da fortuna com o necessário preparo técnico e intelectual, como fazê-los adquirir hábitos de trabalho profícuo, que os afastará da ociosidade, escola do vício e do crime (...)” (Decreto n. 7.566, de 23 de setembro de 1909, que criou nas capitais dos Estados as Escolas de Aprendizes Artífices, núcleos de origem das escolas técnicas federais, atuais CEFETs). Três décadas depois, a Constituição Federal de 10 de novembro de 1937 consagrará o mesmo viés: "O ensino prévocacional e profissional destinado às classes menos favorecidas é matéria de educação, o primeiro dever do Estado" (art. 128), que pode ser identificado hoje, entre outros aspectos, pela ausência da universalização do ensino médio obrigatório e gratuito.

17. Art. $4^{\circ}$, inc. II: a Lei fala na "progressiva extensão da obrigatoriedade e gratuidade ao ensino médio".

18. A exposição de motivos que fundamentam o decreto argumenta que, em termos quantitativos, a proposta implicará, em 2006, a abertura de vinte mil vagas e, a partir de 2007, pelo menos mais quarenta mil vagas anuais. É de se prever que haja aumento no aporte orçamentário para o PROEJA, além dos recursos já destinados às instituiçōes federais de educação tecnológica.

19. Decreto n. 5.225/2004, que alterou dispositivos do Decreto n. 3.860/2001, que dispõe sobre a organização do ensino superior e a avaliação de cursos e instituições.

20. Estas reflexōes sobre o PROEJA constam de Frigotto, Ciavatta e Ramos (2005).

\section{Referências bibliográficas}

BAMBIRRA, V. Teoria de la dependência: uma anticrítica. 2. ed. México: Era, 1983.

BOFF, L. Ressonância Schumann. Jornal do Brasil, Rio de Janeiro, p. A-11, 5 mar. 2004.

Educ. Soc., Campinas, vol. 27, n. 96 - Especial, p. 911-934, out. 2006

Disponível em <http://www.cedes.unicamp.br> 
Os Centros Federais de Educação Tecnológica e o ensino superior...

BOURDIEU, P.; WACQUANT, L. A nova bíblia do Tio Sam. In: Cattani, A.D. (Org.). Fórum Social Mundial: a construção de um mundo melhor. Porto Alegre: Ufrgs; Petrópolis: Vozes, 2001. p. 156-171.

CAMPELLO, A.M.M.B. A "cefetização" das escolas técnicas federais: um percurso do ensino médio-técnico ao ensino superior. 2005. Tese (Doutorado) - Faculdade de Educação, Universidade Federal Fluminense, Niterói.

CARDOSO, F.H.; FALETTO, E. Dependência e desenvolvimento na América Latina: ensaio de interpretação sociológica. 5. ed. Rio de Janeiro: Zahar, 1979.

CARDOSO, M.L. Sobre a teorização do capitalismo dependente em Florestan Fernandes. In: FÁvero, O. Democracia e educação em Florestan Fernandes. Campinas: Autores Associados; Niterói: EDUFF, 2005.

CIAVATTA, M. A educação profissional do cidadão produtivo à luz de uma análise de contexto. Proposta, Rio de Janeiro, v. 29, n. 86, p. 7689, set./nov. 2000.

CIAVATTA, M. Universidade, pecado nativo. Carta Aberta. Trabalho Necessário, Niterói, n. 1, 2003. Disponível em: <www.uff.br/ trabalhonecessario/>

CIAVATTA, M. A formação integrada: a escola e o trabalho como lugares de memória e de identidade. In: Frigotto, G.; CiavatTa, M.; Ramos, M. (Org.). Ensino médio integrado: concepção e contradições. São Paulo: Cortez, 2005.

DUAYER, M. A economia depois do relativismo: crítica ontológica ou ceticismo instrumental? Trabalho apresentado no 8. Congresso Nacional de Economia Política, Florianópolis, jun. 2003.

FRIGOTTO, G. Fundamentos cientificos e técnicos da relação trabalho e educação no Brasil hoje. Rio de Janeiro, 2005. (versão preliminar, mimeo.).

FRIGOTTO, G.; CIAVATTA, M. Educar o trabalhador cidadão produtivo ou o ser humano emancipado? Trabalho, Educação \& Saúde, Rio de Janeiro, v. 1, n. 1, p. 45-60, mar. 2003. 
FRIGOTTO, G.; CIAVATTA, M.; RAMOS, M. A política de educação profissional no governo Lula: um percurso histórico controvertido. Educação \& Sociedade, Campinas, v. 26, n. 92, p. 1087-1113, out. 2005.

GRAMSCI, A. La alternativa pedagógica. Barcelona: Fontamara, 1981.

HILST, V.L.S. A tecnologia necessária. Piracicaba: Unimep, 1994.

LESSA, C. Universidade pública e nação. Entrevista. Jornal do Brasil, Rio de Janeiro, Economia \& Negócios, 9 out. 2005.

LIMA FILHO, D.L. A tecnologia e a educação tecnológica: elementos para uma sistematização conceitual. Educação \& Tecnologia, Belo Horizonte, v. 10, n. 1, p. 19-28, jan./jun. 2005.

LOSANO, M.G. Histórias de autômatos: da Grécia clássica à Belle Époque. São Paulo: Cia das Letras, 1992.

MARINI, R.M. O conceito de trabalho produtivo. In: MARINI, R.M. Dialética da dependência. Petrópolis: Vozes, 2000.

MARX, K. O capital: crítica da economia política. Livro 1: O processo de produção do capital. 6. ed. Rio de Janeiro: Civilização Brasileira, 1980 .

MATSURA, K. Rumo às sociedades do conhecimento. Folha de S. Paulo, São Paulo, 13 nov. 2005, Opinião, p. A-3.

MATTOS, H.M. Escravidão e cidadania no Brasil monárquico. Rio de Janeiro: Jorge Zahar, 2000.

OLIVEIRA, M.B. Ciência: força produtiva ou mercadoria. Revista de Critica Marxista, Campinas, n. 21, p. 77-98, 2005.

PARIS, C. O animal cultural. São Carlos: UfSCAR, 2002.

RORTY, R. Objetivismo, relativismo e verdade: escritos filosóficos. Rio de Janeiro: Relume-Dumará, 1997.

ROSSI, P. Naufrágios sem espectador: a idéia de progresso. São Paulo: UNESP, 2000.

SADER, E. ALCA: integração soberana ou subordinada. São Paulo: Expressão Popular, 2001.

Educ. Soc., Campinas, vol. 27, n. 96 - Especial, p. 911-934, out. 2006 
Os Centros Federais de Educação Tecnológica e o ensino superior...

SANTOS, G.C. A qualificação profissional entre fios invisiveis: uma análise crítica do Plano Nacional de Qualificação do Trabalhador (PLANFOR). 2003. Tese (Doutorado) - Faculdade de Educação, Pontifícia Universidade Católica de São Paulo, São Paulo.

SANTOS, T. La teoría de la dependencia: un balance histórico y teórico. In: Segrera, F.L. (Ed.). Los retos de la globalización: ensayos en homaje a Theotonio dos Santos. Caracas: UNESCO, 1998.

SANTOS, W.G. Ordem burguesa e liberalismo politico. São Paulo: Duas Cidades, 1978.

VENTURA, J.P. O PLANFOR e a educação de jovens e adultos trabalhadores: a subalternidade reiterada. 2001. Dissertação (Mestrado) - Faculdade de Educação, Universidade Federal Fluminense, Niterói. 